Serum level of proinflammatory cytokines such as IL-17 and IL-23 were measured by enzyme-linked immunosorbent assay (ELIZA).

Results: Psychiatric manifestations

BD has significant lower score in all components of MAS and high prevalence of depression and anxiety in HDRS and HARS respectively compared with control group ( $p<0.001$ ). Severe depression was found in $82.9 \%$ of BD patients. Moreover, our data showed $46.7 \%$ of BD patients have moderate anxiety compared to the control group.

Serum Levels of IL-17 and IL-23

The serum level of IL-17 and IL-23 levels were significantly higher among BD patients than in healthy control $(<0.000)$.

There was no significant correlation between those cytokines and cognitive impairment, depression and anxiety.

Conclusion: Elevated level of IL-17 and IL-23 were observed in BD patients. However, our results do not support an association between serum IL-17 and IL-23 levels and cognitive dysfunction, depression and anxiety.

References:

[1] Gheita, T. A., S. M. Gamal, I. Shaker, H. S. El Fishawy, R. El Sisi, O. G. Shaker and S. A. Kenawy (2015). "Clinical significance of serum interleukin-23 and A/G gene (rs17375018) polymorphism in Behcets disease: Relation to neuro-Behcet, uveitis and disease activity." Joint Bone Spine 82(3): 213-215.

[2] Ilhan, B., M. Can, F. Alibaz-Oner, S. Yilmaz-Oner, O. Polat-Korkmaz, G. Ozen, G. Mumcu, H. Maradit Kremers and H. Direskeneli (2016). "Fatigue in patients with Behcet's syndrome: relationship with quality of life, depression, anxiety, disability and disease activity." Int J Rheum Dis.

[3] ITR-ICBD (2014). "The International Criteria for Behcet's Disease (ICBD): a collaborative study of 27 countries on the sensitivity and specificity of the new criteria." J Eur Acad Dermatol Venereol 28(3): 338-347.

[4] Sugita, S., Y. Kawazoe, A. Imai, Y. Yamada, S. Horie and M. Mochizuki (2012). "Inhibition of Th17 differentiation by anti-TNF-alpha therapy in uveitis patients with Behcet's disease." Arthritis Res Ther 14(3): R99

Disclosure of Interests: : None declared

DOI: 10.1136/annrheumdis-2020-eular.254

\section{AB0457 OBSTETRICAL OUTCOME AND TREATMENTS DURING PREGNANCY IN SERONEGATIVE PRIMARY APS: DATA FROM EUROPEAN RETROSPECTIVE STUDY}

N. Abisror ${ }^{1}$, Y. Nguyen ${ }^{1}$, L. Marozio ${ }^{1}$, E. Esteve-Valverde ${ }^{1}$, S. Udry ${ }^{1}$, D. E. Pleguezuelo ${ }^{1}$, P. Billoir ${ }^{1}$, K. Mayer-Pickel ${ }^{1}$, G. Urbanski ${ }^{1}$, P. Zigon ${ }^{1}$, C. De Moreuil $^{1}$, A. Hoxha ${ }^{1}$, H. Bezanahary ${ }^{1}$, L. Carbillon ${ }^{1}$, G. Kayem ${ }^{1}$, M. Bornes ${ }^{1}$, C. Yelnik ${ }^{1}$, C. Johanet ${ }^{1}$, P. Nicaise Roland ${ }^{1}$, M. Lambert ${ }^{1}$, V. Salle ${ }^{1}$, O. Latino ${ }^{1}$, E. Hachlla ${ }^{1}$, C. Benedetto ${ }^{1}$, Y. Benhamou ${ }^{1}$, J. Alijotas-Reig ${ }^{1}$, O. Fain ${ }^{1}$, A. Mekinian ${ }^{1}$. 'Sorbonne Université, AP-HP, Hôpital Saint-Antoine, Service de Médecine Interne and Inflammation-Immunopathology-Biotherapy Department (DMU 3iD), Paris, France

\section{Background:}

Objectives: To compare clinical characteristics, pregnancies, and treatments during pregnancies of seronegative and seropositive APS, and analyse factors associated with adverse obstetrical outcomes.

Methods: Inclusion criteria were: (1) thrombotic arterial and/or venous; and /or obstetrical primary clinical APS (Sydney criteria); (2) absence of conventional antiphospholipid antibodies; (3) presence of at least one non-conventional APL among IgA ACL, IgA antiB2GPI, anti-vimentin $\mathrm{G} / \mathrm{M}$, anti-annexin V G/M, anti-PE G/M, anti-PS/PT G/M antibodies. The exclusion criteria were: (1) seropositive APS with conventional APS; (2) associated SLE or SLE like (SLE features and / or positive antinuclear autoantibodies); (3) other systemic connective tissue disease (Sjogren's syndrome, systemic sclerosis, myositis).

Results: 187 women (mean $33 \pm 5$ years) with seronegative APS were included from 12 centers in the world and compared to 285 patients with seropositive APS. Seronegative APS have mostly obstetrical phenotypes rather than venous thrombosis in comparison to seropositive APS. The maternal and fetal outcomes and the rates of live births were not significantly different in seronegative and seropositive APS, except for higher rates of intrauterine deaths (15\% vs $5 \%$; $p=0.03)$ and lower live birth term $(36 \pm 3$ vs $38 \pm 3$ weeks of gestation; $p=0.04)$ in the seropositive APS group. The cumulative incidence of adverse obstetrical events was significantly improved in treated seronegative APS vs untreated ones (log rank<0.05), whereas there was no difference between patients who received aspirin or aspirin-LMWH combination

Conclusion: Patients with clinical manifestations of APS without conventional APL should undergo testing for non-criteria APL. The diagnosis of seronegative APS could be important for a better care of these patients.
Table 1. Characteristics of seronegative and seropositive APS women.

\begin{tabular}{lcc}
\hline & $\begin{array}{c}\text { Seronegative APS } \\
\mathbf{N}=\mathbf{1 8 7}\end{array}$ & $\begin{array}{c}\text { Seropositive APS } \\
\mathbf{N}=\mathbf{2 8 5}\end{array}$ \\
\hline APS features & & \\
Thrombotic APS & 0 & $105(37)^{\star}$ \\
$\quad$ Arterial APS (n;\%) & $9(6)$ & $154(54)^{\star}$ \\
$\quad$ Venous APS (n;\%) & $168(89)$ & $89(31)^{\star}$ \\
Obstetrical APS (n;\%) & $8(4)$ & $16(6)$ \\
Mix APS (n;\%) & $16(9)$ & $141(49)^{\star}$ \\
Non criteria features (n;\%) & & $18(6)^{\star}$ \\
Obstetrical history & $66(35)$ & $46(16)^{\star}$ \\
$\quad$ Miscarriages (n;\%) & $60(32)$ & $31(11)^{\star}$ \\
Intrauterine deaths (n;\%) & $43(23)$ & \\
Prematurity <34 wg (n;\%) & & \\
\hline
\end{tabular}

Table 2. Pregnancy outcome and treatment in seronegative and seropositive APS.

\begin{tabular}{lcc}
\hline & $\begin{array}{c}\text { Seronegative APS } \\
\text { pregnancies } \\
\mathbf{N}=\mathbf{1 0 8}\end{array}$ & $\begin{array}{c}\text { Seropositive APS } \\
\text { pregnancies } \\
\mathbf{N}=\mathbf{7 5}\end{array}$ \\
\hline Thrombotic APS & & \\
$\quad$ Arterial APS (n;\%) & 0 & $20(27)^{\star}$ \\
$\quad$ Venous APS (n;\%) & $8(7)$ & $42(56)^{\star}$ \\
Obstetrical APS (n;\%) & $93(86)$ & $36(48)^{\star}$ \\
Mix APS (n;\%) & $6(6)$ & $18(24)$ \\
Aspirin (n;\%) / Aspirin alone & $(88) / 32(30)$ & $57(76)^{\star} / 2(3)^{\star}$ \\
LMWH isocoagulant amounts (n;\%) & $63(58)$ & $39(52)$ \\
Aspirin-LMWH (n;\%) & $65(60)$ & $55(73)$ \\
Preeclampsia/HELLP syndrome (n;\%) & $7(7)$ & $12(16)^{\star}$ \\
IUGR (n;\%) & $5(5)$ & $7(10)$ \\
Fetal loss (n;\%) & $33(31)$ & $22(29)$ \\
Miscarriage / Intrauterine deaths & $23(21) / 5(5)$ & $11(15) / 11(15)^{\star}$ \\
Prematurity<34 weeks of gestation (n;\%) & $6(6)$ & $9(12)$ \\
Term of fetal loss (weeks gestation) & $10 \pm 8$ & $13 \pm 7$ \\
Live births (n;\%) & $75(69)$ & $53(70)$ \\
Term of live birth (weeks gestation) & $38 \pm 3$ & $36 \pm 3^{\star}$ \\
\hline
\end{tabular}

Disclosure of Interests: : None declared

DOI: 10.1136/annrheumdis-2020-eular.3537

\section{AB0458 SYSTEMIC TREATMENT IN BEHÇET'S DISEASE ACCORDING TO CLINICAL PHENOTYPES. STUDY OF 111 PATIENTS}

C. Alvarez Reguera ${ }^{1}$, D. Martínez-López ${ }^{1}$, L. Sanchez Bilbao ${ }^{1}$, A. Herrero Morant $^{1}$, J. L. Martín-Varillas ${ }^{1}$, G. Suárez Amorín ${ }^{2}$, P. Setien Preciados ${ }^{1}$, M. C. Mata Arnaiz ${ }^{3}$, M. Á. González-Gay ${ }^{1}$, R. Blanco ${ }^{1}{ }^{1}$ H.U.M. Valdecilla, Rheumatology, Santander, Spain; ${ }^{2}$ H.U. M. Valdecilla, Ophthalmology, Santander, Spain; ${ }^{3}$ Hospital de Laredo, Rheumatology, Laredo, Spain

Background: Behçet's disease (BD) is a multisystemic vasculitis. Different clinical phenotypes can be distinguished. Systemic corticosteroids are the most used drugs in BD. Conventional and biological immunosuppressants (IS) may also be used.

Objectives: To evaluate the systemic treatment of BD according to clinical domains.

Methods: Study of all consecutive 111 patients diagnosed with definitive or possible BD by expert rheumatologists in a well-defined population of Northern Spain, between 1980 and 2019. Most of them met the International Criteria for BD (ICBD) (1).

Results: We studied 111 patients (62 women/49 men), mean age at diagnosis $36.8 \pm 13.2$ years. After a mean follow-up of $81.4 \pm 85$ months, all patients required systemic treatment (TABLE 1-2). Biological therapy $(n=28)$ was indicated by ocular manifestations $(n=13 ; 46.4 \%)$ persistent, severe and refractory oral ulcers $(n=10,35.7 \%)$, neurological $(n=2 ; 7.1 \%)$, musculoskeletal $(n=2 ; 7.1 \%)$ or cutaneous involvement $(1 ; 3.6 \%)$. Adalimumab and Infliximab were the biological therapy more frequently used.

Conclusion: Most patients with BD required oral corticosteroids and colchicine. Almost half required conventional IS. Up to a third required biologic therapy, especially by ocular involvement. Most patients had clinical improvement. References:

[1] Criteria for diagnosis of Behcet's disease, International Study Group for Behçet's Disease, The Lancet, Volume 335, Issue 8697, 1078 - 1080

Disclosure of Interests: Carmen Alvarez Reguera: None declared, David Martínez-López: None declared, Lara Sanchez Bilbao: None declared, Alba Herrero Morant: None declared, José Luis Martín-Varillas Grant/research support from: AbbVie, Pfizer, Janssen and Celgene, Speakers bureau: 